\title{
Sleep Apnea in Morbidly Obese Patients: Prevalence and Clinical Predictivity
}

\author{
Antonio Palla ${ }^{a}$ Michela Digiorgio $^{a}$ Nicoletta Carpenè ${ }^{a}$ Giuseppe Rossi ${ }^{c}$ \\ Ilaria D'Amico ${ }^{a}$ Ferruccio Santini $^{\mathrm{b}}$ Aldo Pinchera $^{\mathrm{b}}$ \\ ${ }^{a}$ Cardiac and Thoracic Department, Section of Respiratory Disease and ${ }^{b}$ Department of Integrated Activities of \\ Endocrinology and Metabolic Diseases, University and Hospital of Pisa and ' Unit of Epidemiology and Biostatistics, \\ Institute of Clinical Physiology, National Research Council (C.N.R.), Pisa, Italy
}

\section{Key Words}

Cardiorespiratory sleep study $\cdot$ Obstructive sleep

apnea-hypopnea syndrome $\cdot$ Structured prediction rule

\begin{abstract}
Background: Little is known about the prevalence of obstructive sleep apnea-hypopnea syndrome (OSAHS) in morbidly obese patients and whether such patients show peculiar clinical findings that may make it easier to suspect and diagnose OSAHS. Objectives: To investigate prevalence of OSAHS in patients with morbid obesity and find a simple structured model for predicting the results of polysomnography. Methods: The study enrolled a group of 101 consecutive inpatients ( 33 males, age range $20-80$ years) with a body mass index $\geq 40$, whose symptoms of OSAHS were not known, and a validation group of 45 patients. Results: Habitual snoring, nocturnal apneas or awakening as well as diurnal sleepiness were frequent findings $(90.1,40.6,50.5$ and $61.4 \%$, respectively). Chronic obstructive pulmonary disease, hypertension, diabetes and myocardial ischemia were also frequently associated $(22.8,56.4,30.7$ and $6.9 \%$, respectively). OSAHS was found in 61 (60.4\%) patients, in $33.7 \%$ it was of severe degree. A multivariate logistic regression model allowed to select the independent predictors of OSAHS: age, male sex, diurnal sleepiness and the value of minimum nocturnal saturation. Sensitivity of $97 \%$, specificity of $77 \%$ as
\end{abstract}

well as positive and negative predictive values of $87 \%$ and $95 \%$, respectively, were obtained; similar results were found in the validation group. When the best obtainable cutoff on the receiver operating characteristic curve is below $40 \%$, the instrumental diagnosis might be excluded in as many as 33\% of cases, since they are not affected by OSAHS or have OSAHS of mild degree. Conclusions: OSAHS is present in almost two thirds of morbidly obese patients. By applying the prediction model we propose, one may calculate the probability of a morbidly obese patient of being affected by OSAHS.

Copyright $\odot 2008$ S. Karger AG, Basel

It is commonly accepted that obesity is one of the major risk factors for obstructive sleep apnea-hypopnea syndrome (OSAHS) [1] and that OSAHS has a higher prevalence among obese subjects than among the general population [2]. In spite of this, little is known on the prevalence of OSAHS in those patients with obesity of severe degree, who more and more frequently present to obesity clinics and medical wards. Likewise, whether morbidly obese patients show peculiar clinical findings that may make it easier to suspect and, thus, diagnose OSAHS, has not been definitely demonstrated.

Identifying peculiar patterns of OSAHS in such patients could be useful in clinical practice; yet, although many authors suggest that such patients must be detected

\section{KARGER}

Fax +4161306 1234 E-Mail karger@karger.ch www.karger.com
(C) 2008 S. Karger AG, Basel 0025-7931/09/0782-0134\$26.00/0

Accessible online at:

www.karger.com/res
Prof. Antonio Palla

Dipartimento Cardio-Toracico e Vascolare

Sezione di Malattie Respiratorie, Università di Pisa, Ospedale Cisanello

Via Paradisa 2, IT-56124 Pisa (Italy)

Tel. +39 050995 363, Fax +39 050995 395, E-Mail a.palla@med.unipi.it 
early, performing polysomnography in all patients at risk is realistically impossible. Several authors have attempted to predict OSAHS on clinical grounds $[3,4]$ with the aim of excluding diagnosis, establishing an a priori probability and prioritizing patients for instrumental diagnosis in order to reduce the pressure on the overcrowded diagnostic centers. Most studies so far have investigated patients with obesity of mild to moderate degree with often conflicting results that show on average a low specificity in making the final diagnosis [5]. A frequent bias of these studies was that patients had been enrolled on the basis of typical symptoms of OSAHS and the criteria used for suspicion had also been employed for elaborating prediction rules. Recently, a report on overtly asymptomatic patients has been published but includes only moderately obese patients [6].

Therefore, we planned a study that included consecutive morbidly obese patients referred for reasons different from suspicion of OSAHS, whose symptoms were unknown to the investigators. In such a sample of patients, we wanted to evaluate: (1) the prevalence and the clinical pattern of OSAHS and (2) the possibility of predicting the disease on the basis of a simple structured model.

\section{Methods}

\section{Study Population}

The study was approved by the local Institutional review board and all patients agreed that data regarding their health status could be used for scientific purposes. The study evaluated consecutive morbidly obese patients referred to the obesity clinic. The only inclusion criterion adopted to enter the study was a value of body mass index $(\mathrm{BMI}) \geq 40$, while the presence of symptoms/signs compatible with OSAHS prior to the study was unknown to the investigators. At a later time, consecutive morbidly obese patients with similar clinical and morphologic characteristics were enrolled and utilized as a validation group.

History and clinical findings were investigated in all patients, with particular attention to symptoms and signs reported in the literature to be frequently associated with OSAHS, such as habitual snoring, apnea reported by bed partner, nocturnal awakenings, diurnal sleepiness and nocturia. In particular, diurnal sleepiness was assessed using the Epworth sleepiness scale (ESS) [7], with the normal range of ESS scores between 2 and 10. In particular, diurnal sleepiness was considered as such when the score was higher than 10. Morphologic data such as BMI, Broca index, neck circumference and neck circumference normalized by height were obtained. Neck circumference was determined at the level of the cricothyroid membrane [8]. According to the Italian guidelines for diagnosis of OSAHS [9], we have considered a neck circumference $>43 \mathrm{~cm}$ in males and $>41 \mathrm{~cm}$ in females as a risk factor for OSAHS.

A respiratory functional evaluation was obtained by spirometry (Pulmonary System 47804A; Hewlett Packard) and diffusing lung capacity of CO (Elite Series ${ }^{\text {TM }}$ Plethysmograph; MedGraphics) following the ATS guidelines [10]. Arterial gas analysis was performed by an IL 1302 apparatus (Instrumentation Laboratories)

All patients underwent a cardiorespiratory sleep study performed at nighttime in the hospital under nurses' control by means of a polygraph (Somno Check; Vivisol). In all cases, a sleep duration of at least $5 \mathrm{~h}$ was requested. In particular, measured variables included oronasal flow by nasal cannula, thoracoabdominal movements, pulse oxymetry, snoring and body position. The results were all scored by the attending physician expert in sleep studies and never left to the instrument alone [11]. Apnea was defined by the absence of airflow for $>10 \mathrm{~s}$. Hypopneas were defined as any airflow reduction of $>50 \%$ that lasted for $>10 \mathrm{~s}$ and resulted in oxyhemoglobin desaturation ( $3 \%$ dip rate). The apneahypopnea index (AHI) was defined as the sum of the numbers of apneas and hypopneas per hour of sleep. OSAHS was diagnosed as present when AHI was $>5$. According to the American Sleep Disorders Association Task Force criteria [12], sleep-related obstructive breathing events were scored as mild when between 5 and 15 events/hour of sleep were present, as moderate when there were between 15 and 30 events/hour of sleep and as severe when $>30$ events/hour of sleep were present. OSAHS was present when sleep monitoring demonstrated 5 or more obstructed breathing events per hour of sleep associated to characteristic symptoms and signs such as excessive daytime sleepiness, choking or gasping during sleep, recurrent awakenings from sleep and impaired concentration. In patients with a negative cardiorespiratory sleep study showing diurnal sleepiness, a complete polysomnography was performed to avoid false-negative diagnosis in accordance with the American Sleep Disorders Association report [13].

\section{Statistical Analysis}

Quantitative variables are expressed as means $\pm \mathrm{SD}$, while qualitative variables are expressed as percentages. Differences in the baseline characteristics in the 2 sexes and between OSAHS and non-OSAHS patients were evaluated in a univariate analysis by t test and Wilcoxon's rank sum test for quantitative variables and by the $\chi^{2}$ test or Fisher's exact test for qualitative variables. Two-sided $p<0.05$ were considered statistically significant.

In order to estimate the probability of OSAHS, a multivariate analysis was performed through the logistic regression model. Qualitative variables were considered as dummy variables, coded as 0 (absent) and 1 (present). The model initially included all variables that were statistically significant or near to significance in the univariate analysis. A backward elimination procedure was used, variables with $\mathrm{p}>0.05$ were removed from the model step by step according to their $\mathrm{p}$ value. The performance of the final model was evaluated by the area under the receiver operating characteristic (ROC) curve and by its ability to correctly classify patients as OSAHS and non-OSAHS patients. The classification of patients was performed assuming as OSAHS patients those with a probability of OSAHS predicted by the final logistic regression model $>0.40$. The cutoff value of 0.40 for the predicted probability of OSAHS was obtained by the ROC curve using the highest sensitivity with the highest specificity as selection criteria. In the ROC analysis the probability of OSAHS predicted by the final logistic model was used as classification variable, while the variable referring to the presence or absence of OSAHS was consid- 
ered as reference variable. The performance indexes used were sensitivity, specificity, positive predictive value, negative predictive value, true prevalence, apparent prevalence, Youden's J index and $\kappa$ concordance index. Youden's J combines information about sensitivity and specificity into a single value (sensitivity + specificity -1 ), and ranges from -1 for a worthless test to 1 for a perfect test. $\kappa$ index expresses the proportion agreement beyond chance. A $\kappa$ of 0 indicates no agreement beyond chance, while a $\kappa$ of 1 indicates perfect agreement. The logistic regression model was cross-validated to check for overfitting of the data by using a validation group of new obese patients that had not been used for estimating the model.

\section{Results}

\section{General Data}

One hundred and one patients were included in the study: 33 were males and 68 females; age ranged between 20 and 80 years; mean weight was $125.1 \pm 21.2 \mathrm{~kg}$ (range 95-207) and mean height was $164 \pm 9 \mathrm{~cm}$ (range 149197). BMI ranged between 40 and 77 and its mean value was significantly higher in females $(\mathrm{p}=0.015)$. Neck circumference, even when normalized by height, was significantly higher in males $(\mathrm{p}=0.002)$, while more than two thirds of patients $(97.0 \%$ of males and $57.4 \%$ of females, $\mathrm{p}<0.0001$ ) showed a neck circumference higher than the cutoff value for females and males.

Previous diagnoses of chronic obstructive pulmonary disease and arterial systemic hypertension were found in 22.8 and $56.4 \%$ of patients, respectively; 30.7 and $6.9 \%$ of subjects presented diabetes mellitus and myocardial ischemia, respectively, which occurred significantly more frequently in males $(\mathrm{p}=0.038$ and $\mathrm{p}=0.005$, respectively).

Most patients showed typical symptoms of OSAHS, such as habitual snoring (90.1\%), nocturnal apneas (40.6\%), nocturnal awakening (50.5\%), diurnal sleepiness $(61.4 \%)$ and nocturia (39.9\%); males had apneas with a significantly higher frequency $(\mathrm{p}=0.019)$.

The evaluation of the pulmonary function (table 1) shows that most spirometric variables were within the normal range, however, with a broad variability. Nevertheless, a statistically significant lower mean value of forced expiratory volume in $1 \mathrm{~s}$ was found in males $(\mathrm{p}=$ 0.009 ), while functional residual capacity (FRC) was lower in females, though not significantly $(\mathrm{p}=0.208)$. Lung diffusion capacity of CO was normal on the average, although $15 \%$ of the subjects presented a slight reduction (data not shown). Mean values of measured arterial oxygen pressure were significantly lower in men (table 1).
Table 1. Pulmonary function data in 101 study patients

\begin{tabular}{lccrc}
\hline & $\begin{array}{l}\text { Total } \\
(\mathrm{n}=101)\end{array}$ & $\begin{array}{l}\text { Male } \\
(\mathrm{n}=33)\end{array}$ & \multicolumn{1}{l}{$\begin{array}{l}\text { Female } \\
(\mathrm{n}=68)\end{array}$} & $\mathrm{p}$ \\
\hline $\mathrm{FEV}_{1}, \%$ pred. & $91 \pm 20.1$ & $83.5 \pm 22.5$ & $94.6 \pm 18.0$ & 0.009 \\
$\mathrm{FEV}_{1}$ /SVC, \% pred. & $97.2 \pm 11.4$ & $95.0 \pm 13.4$ & $98.3 \pm 10.3$ & 0.187 \\
SVC, \% pred. & $97.6 \pm 19.5$ & $90.9 \pm 19.0$ & $100.9 \pm 19.1$ & 0.016 \\
ERV, \% pred. & $53.8 \pm 36.0$ & $54.4 \pm 37.1$ & $54.0 \pm 35.9$ & 0.947 \\
RV, \% pred. & $93.5 \pm 28.7$ & $101 \pm 31.6$ & $90.2 \pm 27.0$ & 0.133 \\
FRC, \% pred. & $74.8 \pm 21.1$ & $79.4 \pm 24.8$ & $72.7 \pm 19.1$ & 0.208 \\
TLC, \% pred. & $96.4 \pm 14.9$ & $95.5 \pm 13.5$ & $96.9 \pm 15.6$ & 0.671 \\
RV/TLC, \% pred. & $101.0 \pm 24.8$ & $107 \pm 25.6$ & $97.6 \pm 23.8$ & 0.056 \\
$\mathrm{DLCO}^{1}, \%$ pred. & $96.5 \pm 17.2$ & $99.0 \pm 18.1$ & $95.2 \pm 16.8$ & 0.371 \\
$\mathrm{KCO}^{1}, \%$ pred. & $99.2 \pm 24.3$ & $97.5 \pm 28.3$ & $100.2 \pm 21.3$ & 0.661 \\
$\mathrm{pH}$ & $7.42 \pm 0.02$ & $7.41 \pm 0.03$ & $7.42 \pm 0.02$ & 0.002 \\
$\mathrm{PaCO}_{2}$, mm Hg & $39.9 \pm 5.8$ & $42.2 \pm 6.4$ & $38.8 \pm 5.2$ & 0.008 \\
$\mathrm{PaO}_{2}, \mathrm{~mm} \mathrm{Hg}$ & $77.8 \pm 12.6$ & $72.6 \pm 12.4$ & $80.5 \pm 11.9$ & 0.003 \\
\hline
\end{tabular}

Data are means \pm SD.

$\mathrm{FEV}_{1}=$ Forced expiratory volume in $1 \mathrm{~s}$; pred. $=$ predicted; $\mathrm{SVC}=$ slow vital capacity; ERV = expiratory reserve volume; $\mathrm{RV}=$ residual volume; TLC= total lung capacity; DLCO = lung diffusion capacity of $\mathrm{CO} ; \mathrm{KCO}=$ carbon monoxide transfer coefficient; $\mathrm{PaO}_{2}=$ arterial oxygen tension; $\mathrm{PaCO}_{2}=$ arterial carbon dioxide tension.

${ }^{1}$ Lung capacity diffusing of $\mathrm{CO}$ data refer to 72 subjects.

OSAHS was found in 61 (60.4\%) patients (AHI: 28.3 $\pm 29)$ and showed a higher prevalence in men $(78.8 \%$ of males and $51.5 \%$ of females). Of all patients, $13.9 \%$ were of mild, $12.9 \%$ of moderate and $33.7 \%$ of severe degree; furthermore, the prevalence of OSAHS of severe degree in males was 2 -fold higher ( 48.8 vs. $26.5 \%$ ). Mean nocturnal saturation was significantly lower in men $(90.5 \pm 4.9$ vs. $92.6 \pm 3.6, \mathrm{p}<0.05)$. Minimum nocturnal saturation $\left(\mathrm{SpO}_{2} \mathrm{~min}\right)$ was lower in men, though not significantly (70.8 \pm 13.8 vs. $75.5 \pm 12.2)$. Among 40 (39.6\%) patients in whom OSAHS was excluded, 11 showed diurnal sleepiness and, therefore, underwent polysomnography that confirmed the negativity. This procedure was also applied to the 45 patients of the validation group. Among the 11 patients in whom OSAHS was excluded, 3 underwent polysomnography that showed negative results.

\section{Prediction of OSAHS}

By dividing patients into 2 groups, OSAHS and nonOSAHS, we evaluated the distribution of variables associated with both groups, as reported in tables 2 and 3. In order to identify the findings independently associated with an increased likelihood of OSAHS, we included the significant variables listed above in the multiple logistic regression model. Through a backward elimination procedure, a model with 3 clinical variables (age, male sex 


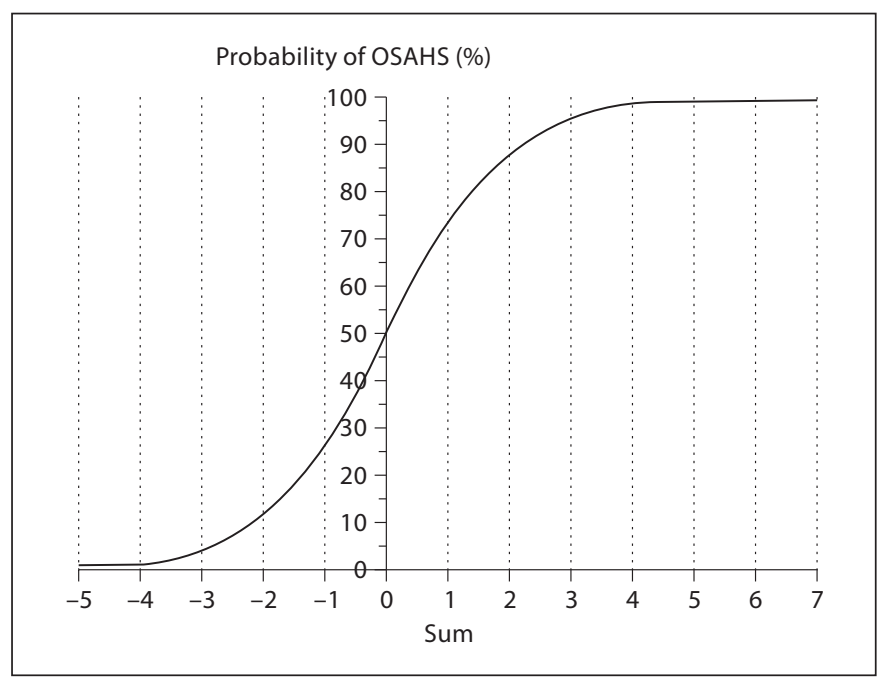

Fig. 1. Probability of OSAHS predicted by the logistic regression model. For example, a 50-year-old man with an ESS value of 18 and an $\mathrm{SpO}_{2}$ min value of $80 \%$ would have a sum value equal to $5.418+0.06 \times 50($ age $)+1.756 \times 1(\operatorname{man})+0.127 \times 18($ ESS $)-$ $0.128 \times 80\left(\mathrm{SpO}_{2} \mathrm{~min}\right)=2.22$. His probability of OSAHS is $1 /$ $\left(1+\mathrm{e}^{-2.22}\right)=0.90$, that is $90 \%$.

and diurnal sleepiness) and $\mathrm{SpO}_{2}$ min as independent predictors of OSAHS was obtained. According to such a model, the constant was equal to 5.418 with the coefficients as follows: age $(0.060, \mathrm{p}=0.016)$, male sex $(1.756$, $\mathrm{p}=0.017)$, diurnal sleepiness $(0.127, \mathrm{p}=0.038)$ and $\mathrm{SpO}_{2}$ $\min (-0.128, \mathrm{p}<0.0001)$. The probability of OSAHS for a given patient can be obtained by applying the following formula, $1 /\left(1+\mathrm{e}^{-\mathrm{sum}}\right)$, or by using the simple method reported in figure 1 , which displays the relation between sum and predicted probability of OSAHS. Sum is the linear combination of model coefficients multiplied for the values of respective variables. To give an example, a 50 year-old man with an ESS value of 18 and an $\mathrm{SpO}_{2}$ min value of $80 \%$ would have a sum value equal to $5.418+0.06$ $\times 50($ age $)+1.756 \times 1($ man $)+0.127 \times 18($ ESS $)-0.128$ $\times 80\left(\mathrm{SpO}_{2} \mathrm{~min}\right)=2.22$. His predicted probability of OSAHS is $1 /\left(1+\mathrm{e}^{-2.22}\right)=0.90$, that is $90 \%$. The area under the ROC curve for the logistic regression model was 0.91 (95\% confidence interval $0.85-0.97$; fig. 1 ). The cutoff value for the predicted probability of OSAHS with the highest sensitivity and specificity was 0.40 , equivalent to a sum value of 0.40 . Consequently, patients with a predicted probability of OSAHS $>0.40$ were classified as patients with OSAHS. The performance indices of the model obtained using this cutoff value are reported in table 4 . When we applied the model to the validation group of 45 obese subjects with similar morphologic and clinical
Table 2. Qualitative variables in OSAHS and non-OSAHS patients

\begin{tabular}{lcll}
\hline & $\begin{array}{l}\text { Non-OSAHS } \\
(\mathrm{n}=40)\end{array}$ & $\begin{array}{l}\text { OSAHS } \\
(\mathrm{n}=61)\end{array}$ & $\mathrm{p}$ \\
\hline Male sex & $7(18)$ & $26(43)$ & 0.008 \\
Snoring & $31(77.5)$ & $60(98.4)$ & 0.001 \\
Nocturnal awakening & $11(27.5)$ & $40(65.5)$ & 0.000 \\
Apneas & $8(20)$ & $33(54)$ & 0.001 \\
Nocturia & $17(42.5)$ & $50(82)$ & 0.000 \\
Hypertension & $16(40)$ & $41(67.2)$ & 0.007 \\
COPD & $11(27.5)$ & $12(20)$ & 0.359 \\
Diabetes & $9(22.5)$ & $22(36.1)$ & 0.148 \\
Myocardial ischemia & $1(2.5)$ & $6(9.8)$ & 0.156 \\
Pathological sleepiness & $25(62.5)$ & $53(87)$ & 0.007 \\
Neck circumference & & & \\
\multicolumn{1}{c}{$>$ maximal limit } & $21(53)$ & $47(77)$ & 0.016 \\
\hline
\end{tabular}

Figures in parentheses are percentages.

$\mathrm{COPD}=$ Chronic obstructive pulmonary disease

Table 3. Quantitative variables in OSAHS and non-OSAHS patients

\begin{tabular}{|c|c|c|c|}
\hline & $\begin{array}{l}\text { Non-OSAHS } \\
(\mathrm{n}=40)\end{array}$ & $\begin{array}{l}\text { OSAHS } \\
(\mathrm{n}=61)\end{array}$ & $\mathrm{p}$ \\
\hline Age & $43.1 \pm 4.2$ & $53.2 \pm 10.9$ & 0.000 \\
\hline Pack-years & $10.8 \pm 5.9$ & $16.0 \pm 27.9$ & 0.294 \\
\hline $\mathrm{BMI}$ & $46.4 \pm 5.9$ & $47 \pm 6.9$ & 0.645 \\
\hline Sleepiness (ESS) & $8.7 \pm 4.8$ & $13.1 \pm 5.1$ & 0.000 \\
\hline Neck, cm & $42.6 \pm 3.8$ & $46.3 \pm 5.3$ & 0.000 \\
\hline Neck/height & $26.1 \pm 2.2$ & $28.0 \pm 2.8$ & 0.002 \\
\hline $\mathrm{PaO}_{2}, \mathrm{~mm} \mathrm{Hg}$ & $81.7 \pm 13.4$ & $75.2 \pm 11.4$ & 0.013 \\
\hline $\mathrm{PaCO}_{2}, \mathrm{~mm} \mathrm{Hg}$ & $38.5 \pm 5.2$ & $40.9 \pm 6.0$ & 0.057 \\
\hline $\mathrm{pH}$ & $7.41 \pm 0.02$ & $7.42 \pm 0.02$ & 0.511 \\
\hline $\mathrm{FEV}_{1}, \%$ pred. & $93.8 \pm 20.6$ & $89.2 \pm 19.8$ & 0.269 \\
\hline $\mathrm{FEV}_{1} / \mathrm{SVC}, \%$ pred. & $98 \pm 12.9$ & $96.7 \pm 10.4$ & 0.581 \\
\hline TLC, \% pred. & $97.9 \pm 14.6$ & $95.5 \pm 15.1$ & 0.429 \\
\hline VC, \% pred. & $102.3 \pm 18$ & $94.5 \pm 19.9$ & 0.053 \\
\hline RV/TLC, \% pred. & $98.9 \pm 28.7$ & $102.4 \pm 22.1$ & 0.507 \\
\hline DLCO, \% pred. & $94.3 \pm 4.5$ & $97.9 \pm 18.8$ & 0.388 \\
\hline KCO, \% pred. & $103.2 \pm 22.2$ & $96.6 \pm 25.4$ & 0.263 \\
\hline $\mathrm{SpO}_{2}$ mean, $\%$ & $94.2 \pm 2.4$ & $90.4 \pm 4.4$ & 0.000 \\
\hline $\mathrm{SpO}_{2} \min , \%$ & $82.8 \pm 7.4$ & $68.1 \pm 12.5$ & 0.000 \\
\hline
\end{tabular}

Figures are means \pm SD.

VC = Vital capacity. For all other abbreviations, see table 1.

characteristics who were enrolled at a later time (30 females and 15 males, mean age $48.2 \pm 9.9$ years, mean BMI $50.2 \pm 7.2$, mean weight $139.2 \pm 22.0 \mathrm{~kg}$ and mean height $166 \pm 7.8 \mathrm{~cm}$ ), we obtained similar results (ta- 
Table 4. Performance of the logistic regression model applied to 101 patients and to the validation group of 45 patients

\begin{tabular}{lcl}
\hline & Patient group & Validation group \\
\hline Sensitivity, \% & $97(92-100)$ & $85(73-97)$ \\
Specificity, \% & $77(65-90)$ & $91(74-100)$ \\
True prevalence, \% & $60(50-70)$ & $76(63-88)$ \\
Apparent prevalence, \% & $67(58-76)$ & $67(53-80)$ \\
Positive predictive value, \% & $87(79-95)$ & $97(90-100)$ \\
Negative predictive value, \% & $95(86-100)$ & $67(43-90)$ \\
Youden's J & $0.74(0.60-0.88)$ & $0.76(0.55-0.97)$ \\
$\kappa$ & $0.76(0.63-0.89)$ & $0.68(0.44-0.91)$ \\
\hline
\end{tabular}

Figures in parentheses are $95 \%$ confidence intervals.

The classification by logistic regression was performed considering as patients with OSAHS those patients with a predicted OSAHS probability $>0.40$.

Table 5. Comparison between probability estimates and actual prevalence of OSAHS

\begin{tabular}{|c|c|c|c|c|c|c|c|c|c|c|}
\hline \multirow[t]{2}{*}{$\begin{array}{l}\text { Probability } \\
\text { of OSAHS }\end{array}$} & \multicolumn{2}{|c|}{ Patients } & \multicolumn{2}{|c|}{$\begin{array}{l}\text { No } \\
\text { OSAHS }\end{array}$} & \multicolumn{2}{|c|}{$\begin{array}{l}\text { Mild } \\
\text { OSAHS }\end{array}$} & \multicolumn{2}{|c|}{$\begin{array}{l}\text { Moderate } \\
\text { OSAHS }\end{array}$} & \multicolumn{2}{|c|}{$\begin{array}{l}\text { Severe } \\
\text { OSAHS }\end{array}$} \\
\hline & $\mathrm{n}$ & $\%$ & $\mathrm{n}$ & $\%$ & $\mathrm{n}$ & $\%$ & $\mathrm{n}$ & $\%$ & $\mathrm{n}$ & $\%$ \\
\hline \multicolumn{11}{|c|}{ Study group } \\
\hline$\leq 40 \%$ & 33 & 33 & 31 & 94 & 2 & 6 & & & & \\
\hline$>40 \%$ & 67 & 67 & 9 & 13 & 12 & 18 & 13 & 19 & 33 & 39 \\
\hline \multicolumn{11}{|c|}{ Validation group } \\
\hline$\leq 40 \%$ & 15 & 33 & 10 & 67 & 5 & 33 & & & & \\
\hline$>40 \%$ & 30 & 67 & 1 & 3 & 6 & 20 & 2 & 7 & 21 & 70 \\
\hline
\end{tabular}

ble 4), thus demonstrating the practical applicability of the model. Since evaluating whether the actual prevalence of OSAHS was consistent with the probability of OSAHS predicted by the logistic regression model could be relevant from a clinical point of view, we divided the predicted probability into 2 categories: $\leq 40$ and $>40 \%$. Table 5 reports the actual prevalence of OSAHS among patients in each probability category for the logistic regression model. Among the subjects with a predicted probability of OSAHS $\leq 40 \%$, only $6 \%$ were affected by OSAHS (false-negative patients), which was, however, of mild degree. Among the subjects with a probability of OSAHS $>40 \%, 13 \%$ did not present OSAHS (falsepositive patients). Results obtained in the validation group are reported in table 5 . Thirty-three percent of patients - those with a predicted probability of OSAHS $\leq 40 \%$ (true-negative and false-negative patients) - could safely avoid or postpone the instrumental diagnosis in that none of the false-negative patients showed an OSAHS of moderate or severe degree.

\section{Discussion}

Patients with morbid obesity are becoming more frequent and are often referred to overcrowded centers for diagnosis. So far, recognizing OSAHS is still difficult, as it is realistically unfeasible to provide an instrumental diagnosis for all these patients. Therefore, it would be extremely useful to know the typical symptoms or early signs of the disease and be able to select patients on the basis of simple, practical rules.

Our results showed a $60 \%$ prevalence of OSAHS among morbidly obese patients, with a significant difference between the 2 sexes: $80 \%$ of males and $50 \%$ of females. As to degree of severity, this was almost twice as high among males, perhaps due to factors such as body fat distribution and influences of hormones on upper airway resistance [14-17]. So far, the prevalence of sleep-disordered breathing has been estimated in obese patients, but rarely in extremely overweight people not selected on the basis of typical symptoms of OSAHS. A recent study on subjects with BMI $>35$ reported a $70 \%$ prevalence of the disease [18]; however, all components of this group had been included since the subjects were overtly symptomatic of OSAHS.

Our patients, although not selected on the basis of symptoms or signs, showed findings typical of the disease in most cases. Moreover, several comorbidities were detected. Arterial blood hypertension was found in more than half the subjects, equally distributed in both sexes. Several studies have shown the association between OSAHS and hypertension; for example, the study by Dincer and O'Neill [19] showed that OSAHS continues to be a significant heart risk factor as intermittent hypoxemia may increase in sympathetic drive. In our population, diabetes mellitus was most frequent, twice as frequent in males; myocardial ischemia was present almost uniquely among males, in agreement with the figures reported in the literature [20-22].

Spirometry showed average values within the normal range, with the exception of a reduction of expiratory reserve volume and FRC. A restrictive syndrome was found in only $13 \%$ of cases, but reduction below the range of normal values of expiratory reserve volume and FRC were found in 52 and $48 \%$ of the cases, respectively. A minor role seemed to be played instead by air flow limita- 
tion indices. The mean value of the measured arterial oxygen pressure was significantly lower in men than in women, perhaps due to the higher presence of cardiorespiratory comorbidities and smoking addiction in males.

Another objective of our study was to predict OSAHS in the above population by simple, inexpensive methods, which would allow to avoid, or postpone, the need for instrumental sleep studies in this subset of patients. So far, such studies have never been conducted on consecutive morbidly obese patients who were enrolled for reasons different from the symptoms they complained. As a matter of fact, some studies worked out prediction models of OSAHS obtained from groups of patients enrolled because they complained of OSAHS symptoms and had a BMI ranging from normal to very high $[23,24]$, whereas other studies were conducted on severely obese patients complaining of typical signs of OSAHS [18, 25, 26]. A recent study performed on asymptomatic subjects suffering from obesity of moderate degree has found predictive factors in the waist-hips ratio, male gender, neck circumference and nocturnal reduction of saturation; the sensitivity and specificity of the model shown were fairly good [6].

By applying our prediction model, we were able to calculate the probability of each of our patients in the series affected by OSAHS. The model, which considers age, sex, diurnal sleepiness and $\mathrm{SpO}_{2}$ min, obtained a sensitivity of $97 \%$ and a specificity of $77 \%$, with a positive predictive value of $87 \%$ and a negative predictive value of $95 \%$. Similar results (better specificity and positive predictive value) were obtained in the validation group of patients with similar characteristics, therefore confirming the practical applicability of the model.

\section{How to Use the Prediction Rule}

Our prediction rule shows to be both effective and safe. As to the effectiveness, the probability of a subject being affected by OSAHS can be simply calculated by using the graph in figure 1: since the best cutoff for the predicted probability of OSAHS was 0.4 , patients having a probability of OSAHS $\leq 40 \%$ would not require polysomnography. In fact, the degree of correspondence between the actual and estimated probability of OSAHS in these patients is high: false-negative patients account for only $3 \%(2 / 60)$ in the study group and $15 \%(5 / 34)$ in the validation group, and all have a disease of mild degree. Conversely, patients with a probability of OSAHS $>40 \%$ should be referred to a sleep study, since the correspon- dence between the actual and the estimated probability of the disease is quite poor, due to $23 \%$ (9/40) and $9 \%$ (1/11) of false-positive patients in the study and the validation groups, respectively. The application of this rule allowed us to avoid requesting the instrumental diagnosis in $33 \%$ of patients in our series, relieving the already overcrowded diagnostic centers from any further burden. Such a percentage of patients not requiring the instrumental diagnosis appears to be the greatest possible. In fact, if we consider the patients of both the study and validation groups together, the instrumental diagnosis should have been done in 94 patients affected by OSAHS, while, on the basis of our decision rule, 97 patients should have been submitted to the instrumental examination, that is only $3 \%$ more than the expected percentage.

In terms of safety, the model shows $100 \%$ sensitivity, since no patient with moderate or severe OSAHS risks to be missed. Conversely, a few patients will be undergoing an unnecesssary cardiorespiratory sleep study or polysomnography, which, however, appears to be an acceptable bias.

\section{Limitations of the Study}

The diagnosis of OSAHS was not established with polysomnography in all cases, since this is not routinely performed in most centers, ours included. However, in the presence of symptomatic patients - namely those with diurnal sleepiness - we do consider a positive cardiorespiratory sleep study performed at nighttime in hospital as diagnostic, and a negative one as requiring further investigation by polysomnography, which was indeed performed in the present study [13]. Conversely, when symptoms are scarce or absent, we consider it reasonable to rely on a negative cardiorespiratory sleep study alone.

One could argue that the necessity of performing nocturnal pulse oxymetry may limit the applicability of the rule. Nonetheless, the cost of such examination is futile and, since several attempts of predicting the diagnosis of OSAHS on the basis of clinical formulas alone have given discouraging results [5, 24-25], we believe that the rule that we present may be a fairly good practical compromise.

It should though be stressed that the present study is only applicable in obese patients with a BMI $>40$, which, however, are more and more frequently referred to the obesity clinics and are often hospitalized and submitted to investigations of high social costs. 
Finally, few patients of our series might be affected by both OSAHS and hypoventilation syndrome. Although this may be relevant in order to choose the right ventilation therapy once the diagnosis is made, it does not change results as far as the prediction rule is concerned.

\section{Acknowledgment}

We are grateful to Dr. Manuella Walker for the final linguistic revision.

\section{References}

1 Busetto L, Enzi G, Inelmen EM, Costa G, Negrin V, Sergi G, Vinello A: Obstructive sleep apnea syndrome in morbid obesity: effects of intragastric ballon. Chest 2005;128: 618-623.

2 Rajala R, Partinen M, Sane T, Pelkonen R, Huikuri K, Seppäläinen AM: Obstructive sleep apnoea syndrome in morbidly obese patients. J Internal Med 1991;230:125-129.

- 3 Deegan PC, McNicholas WT: Predictive value of clinical features for the obstructive sleep apnoea syndrome. Eur Respir J 1996;9: 117-124.

4 Flemons WW, McNicholas WT: Clinical prediction of the sleep apnea syndrome. Sleep Med 1997;1:19-32.

$\checkmark 5$ Rowley JA, Aboussouan LS, Badr MS: The use of clinical prediction formulas in the evaluation of obstructive sleep apnoea. Sleep 2000;23:929-938.

-6 Sharma SK, Kurian S, Malik V, Mohan A, Banga A, Pandey RM, Handa KK, Mukhopadhyay S: A stepped approach for prediction of obstructive sleep apnea in overtly asymptomatic obese subjects: a hospital based study. Sleep Med 2004;5:351-357.

7 Johns MW: A new method for measuring daytime sleepiness: the Epworth Sleepiness Scale. Sleep 1991;14:540-545.

8 Davies RJO, Stradling JR: The relationship between neck circumference, radiographic pharyngeal anatomy and the obstructive sleep apnoea syndrome. Eur Respir J 1990;3: 509-514.

9 Aiolfi S, Aliani M, Cinti C, Vanessa PA, Neri $\mathrm{M}$, Insalaco G: Sindrome dell'apnea ostruttiva nel sonno (OSAS). Aspetti diagnostici, terapeutici ed educazionali. Rassegna Patol Apparato Respir 2001;16:191-211.
10 American Thoracic Society: Lung function testing: selection of reference values and interpretative strategies. Am Rev Respir Dis 1991;144:1202-1218.

11 Ficher JH, Wiest GH, et al: Evaluation of a portable recording device (SomnoCheck) for use in patient with suspected obstructive sleep apnoea. Respiration 2001;68:307-312.

12 Sleep-related breathing disorders in adults: recommendations for syndrome definition and measurement techniques in clinical research. The Report of an American Academy of Sleep Medicine Task Force. Sleep 1999;22: 667-689.

13 Practice parameters for the indications for polysomnography and related procedures. An American Sleep Disorders Association report. Sleep 1997;20:406-422.

14 Millman RP, Carlisle CC, McGarvey ST, Eveloff SE, Levinson PD: Body fat distribution and sleep apnea severity in woman. Chest 1995; 107:362-366.

15 Popovic RM, White DP: Influence of gender on waking genioglossal electromyogram and upper airway resistance. Am J Respir Crit Care Med 1995;152:725-731.

16 Johnson MW, Anch AM, Remmers JE: Induction of the obstructive sleep apnea syndrome in a woman by exogenous androgen administration. Am Rev Respir Dis 1984; 129:1023-1025.

17 Cistulli PA, Grunstein R, Sullivan CE: Effect of testosterone administration on upper airway collapsibility during sleep. Am J Respir Crit Care Med 1994;149:530-532.
18 Dixon JB, Schachter LM, O’Brien PE: Predicting sleep apnea and excessive day sleepiness in the severely obese: indicators for polysomnography. Chest 2003;123:11341141.

19 Dincer HE, O’Neill W: Deleterious effects of sleep disordered breathing on the heart and vascular system. Respiration 2006;73:124130.

20 O'Brien PE, Dixon JB: The extent of the problem of obesity. Am J Surg 2002;184:4S$8 \mathrm{~S}$.

21 Roux F, D’Ambrosio C, Mohsenin V: Sleeprelated breathing disorders and cardiovascular disease. Am J Med 2000;108:396-402.

- 22 Levinson PD, McGarvey ST, Carlisle CC, Eveloff SE, Herbert PN, Millman RP: Adiposity and cardiovascular risk factors in men with obstructive sleep apnea. Chest 1993; 103:1336-1342.

23 Rodsutti J, Hensley M, Thakkinstian A, D’Este C, Attia J: A clinical decision rule to prioritize polysomnography in patient with suspected sleep apnea. Sleep 2004;27:694699.

24 Viner S, Szalai JP, Hoffstein V: Are history and physical examination a good screening test for sleep apnea? Ann Intern Med 1991; 115:356-359.

25 Serafini FM, MacDowell Anderson W, Rosemurgy AS, Strait T, Murr MM: Clinical predictors of sleep apnea in patients undergoing bariatric surgery. Obes Surg 2001;11:28-31.

26 Herer B, Roche N, Carton M, Roig C, Poujol V, Huchon G: Value of clinical, functional, and oximetric data for the prediction of obstructive sleep apnea in obese patients. Chest 1999;116:1537-1544. 